\section{Focus Groups and Staff Surveys: Tools to Assess the Future Direction of Volunteer Involvement}

\author{
Stephanie G. Jutila ${ }^{1}$, Mary Hockenberry Meyer ${ }^{2}$, and \\ Emily Hoover ${ }^{3}$
}

ADDITIONAL INDEX WORDs. botanic gardens, arboreta, staff, management, Master Gardeners

SUMMARY. Focus groups and surveys were used to align volunteers' work with the mission and organizational objectives of the Minnesota Landscape Arboretum (MLA) at the University of Minnesota. In focus groups, a cross-section of volunteers discussed several issues, including how they could more directly contribute to the mission and organizational objectives of the institution. Staff were surveyed on their perceptions of the volunteer workforce, including their current use of volunteers. Focus groups and surveys proved to be valuable tools to approach programmatic changes in volunteer involvement at the MLA by providing a platform to discuss the areas where change is needed, as well as what kind of change should occur. Focus groups can be a key tool in involving volunteers, by allowing them to provide input on changes that directly affect them, in addition to furthering the understanding of volunteer needs and motivations.

$\mathrm{E}$ ffective volunteer management is critical to advancing the mission and organizational objectives of botanic gardens and arboreta. With reduction in state budgets and competition for private donations, volunteers continue to play an important role in getting the day-to-day work done at many horticultural institutions. The 1991 Points of Light Foundation "The Changing Paradigm" project found that organizations where volunteers directly contribute to the mission and priorities of the organization are the most effective at volunteer involvement (Allen, 1995; Vineyard, 1993). Volunteers' work needs to align with the mission and objectives of the institution in order to build upon an institution's mission-driven offerings (Socolofsky, 1991).

Communicating the mission and organizational objectives is a means of marketing the institution to the volunteers, while establishing guidelines by which to measure the productivity of the volunteers and thus the institution

Department of Horticulture Science, University of Minnesota, St. Paul, MN 55108.

${ }^{1}$ Research assistant.

${ }^{2}$ Associate professor.

${ }^{3}$ Professor and Director of Education, Minnesota Landscape Arboretum.
(Connelly, 1989). The Desert Botanic Garden, in Phoenix, Ariz. (DBG), found that volunteers were giving of their time, but not necessarily to activities that supported the DBG's mission or objectives (Socolofsky, 1991). In response to this finding, the DBG's volunteer program was realigned to not only meet the needs of the institution, but specifically to move the mission forward. To assist in meeting a garden's mission and objectives, articulating these both clearly and directly to the volunteers is necessary (Cummins, 1998).

Good volunteer management is essentially good people management. Volunteers need to receive communication, incentives/rewards, and empowerment (Nelson et al., 1995). Specifically, institutions need to communicate with volunteers to identify and attend to volunteer needs and educate volunteers about the services, events, number of hours volunteered for 2000-03. and issues of the institution (Schrock, 1998; Sirken and McDermott, 1996). To establish and maintain commitment from volunteers, institutions need to recognize the needs, interest, and skills of individual volunteers in addition to rewarding a job well done (Kipperman, 1995; Schrock, 1998). By meeting these needs, volunteers are likely to be retained for longer periods of time (Clary and Miller, 1986; Clary et al., 1992; Francies, 1983; Omoto and Snyder, 1990). The commitment is further established by empowering volunteers through orientation, training and support, and inspiring volunteers with organizational values (Kipperman, 1995; Nelson et al., 1995; Schrock, 1998).

In 2003, at the MLA's 45th anniversary, there were 183 employees and approximately 850 active volunteers (active is defined as any volunteer that has recorded volunteer hours within two calendar years). During 2003, the ratio of MLA volunteer hours to staff hours was 1:7. There is a continual need to recruit new volunteers as a means of replenishing the supply of volunteers, as well as meeting the expanding needs of the MLA. From 2000-03 the MLA volunteer program grew from 475 volunteers to 520 , an average increase of 15 volunteers per year (Table 1). During the same time period, the total number of volunteer hours rose on average $1500 \mathrm{~h}$ per year, from 29,451 to 34,112. Approximately $69 \%$ of the volunteers are female, $24 \%$ are male (Table 1 ).

Given the tremendous contribution of volunteers, we identified volunteer focus groups and staff surveys as tools to assess the future direction of volunteer involvement.

Focus groups were selected based upon their proven success to improve the planning and design of programs (Faber and Wycoff, 1991; Krueger, 1994). As defined by Krueger, focus groups are carefully planned discus-

Table 1. Profile of volunteers at the Minnesota Landscape Arboretum and total

\begin{tabular}{lccccc}
\hline Year & $\begin{array}{c}\text { Female } \\
\text { (no.) }\end{array}$ & $\begin{array}{c}\text { Male } \\
\text { (no.) }\end{array}$ & $\begin{array}{c}\text { Not reported } \\
\text { (no.) }\end{array}$ & $\begin{array}{c}\text { Total } \\
\text { (no.) }\end{array}$ & $\begin{array}{c}\text { Total } \\
\text { volunteer time (h) }\end{array}$ \\
\hline 2000 & 316 & 119 & 40 & 475 & 29,451 \\
2001 & 342 & 107 & 40 & 439 & 30,964 \\
2002 & 353 & 121 & 39 & 513 & 33,031 \\
2003 & 367 & 119 & 34 & 520 & 34,112 \\
\hline
\end{tabular}


sions designed to obtain perceptions on a defined area of interest in a non-threatening environment. Focus groups have gained popularity in private sector marketing as an effective qualitative research tool (Krueger, 1994). Focus groups provide greater insight and a means of evaluating programs compared to other research methods, such as personal interviews and surveys (Andreasen, 1983). Focus groups have been previously used in the field of horticulture (Barton et al., 1996; Haynes and Trexler, 2003; Meyer and Barker, 1997). Although focus groups often have a smaller sample size than other research tools, such as surveys, the in-depth nature of information obtained is of great value to institutions (Krueger, 1994).

Surveys offer the advantages of being cost effective, convenient, and anonymous, while providing significant legitimacy and credibility (Rea and Parker, 1992). Specifically, surveys can achieve a high response rate, while giving staff flexibility to respond when their schedule permits (Maxim, 1999). Surveys are used across many disciplines, with widespread acceptance in academic settings (Czaja and Blair, 1996; Rea and Parker, 1992). We selected surveys to probe staff attitudes toward using and managing volunteers.

The objective of this research was to determine if interviewing focus groups of volunteers and surveying staff could produce information to enhance a volunteer's experience, while aligning their involvement with the mission and organizational objectives at the MLA.

\section{Materials and methods}

Potential focus group participants were identified from MLA's active volunteer database for the previous year (2003), although names were purposely omitted. Participants were selected from a wide range of volunteer activities; however, a minimum number of years of service was not a requirement to attend a focus group. Participants were contacted by phone and asked if they were interested and able to participate. If their response was positive, a personalized followup letter on MLA stationary was sent providing more specifics on the focus group, including a reminder of the date and location for their assigned group, as suggested by Krueger (1994). One

Table 2. Facilitator questions used at the Minnesota Landscape Arboretum (MLA) with volunteer focus groups to determine their needs and alignment with the mission statement.

\section{Opening}

1. How long have you volunteered at the MLA and in what roles?

a. What is meaningful or rewarding to you as a MLA volunteer?

\section{Volunteer program}

2. What is the best way to communicate to you about volunteer opportunities?

3. How can the MLA make it easier for you to record volunteer hours?

4. Do you feel appreciated for your MLA volunteer work?

5. How important is it for volunteers to have a central area to leave personal belongings while volunteering and to sign up for future volunteer opportunities?

a. As a volunteer are you willing to sign yourself up for volunteer shifts either at a central location in the Snyder Building or on-line?

MLA mission and organizational objective

*Prior to asking the next set of questions the moderator will share the MLA's mission

6. Does the MLA's mission make sense to you?

a. Are there any parts of the mission that are confusing?

b. To what extent do you feel comfortable with the mission? $1-5$ scale

c. To what extent are you in agreement with the mission? $1-5$ scale

7. How do you see your volunteer work contributing to the MLA's mission?

8. In what new ways could the volunteers help further the MLA's mission?

*Prior to asking the next set of questions the moderator will share the MLA's organizational objectives from the strategic plan

9. Do the MLA's organizational objectives make sense to you?

a. Are there any that are confusing or incomplete?

b. To what extent do you feel comfortable with the organizational objective?

c. To what extent are you in agreement with the organizational objectives? 1-5 scale

10. How do you see your volunteer work contributing to the MLA's organizational objectives?

11. In what new ways could the volunteers help further the MLA's organizational objectives?

\section{Resource needs}

12. What do the volunteers need to help the MLA in these new ways?

a. What kind of training and resources do the volunteers need to help the MLA in these new ways?

b. What currently hinders the volunteers from furthering the MLA's mission and organizational objectives to the greatest extent possible?

13. What can be done to improve the volunteer experience at the MLA?

\section{Concluding}

14. All things considered, what are the main ways in which volunteers can help further the MLA's mission and organizational objectives?

15. Do you have an interest or see a need for a volunteer advisory board at the MLA?

week before the focus groups, participants were called to remind them of the meeting. To accommodate a broad cross-section of volunteers, three focus groups were held: evening, morning, and early afternoon, over $2 \mathrm{~d}$. Although the number varied in each focus group, each person had an equal opportunity to answer each question.

The room was set up with chairs arranged in a circle, with a low coffee table in the center for handouts and writing utensils. A list of predetermined questions was used to focus the discus- sion (Table 2). Participants were given the MLA's mission and vision along with a condensed version of the organizational objectives, which were taken from the MLA's 2003 strategic plan. The full strategic plan was available for participants if they desired a copy at the conclusion of the focus group.

Each focus group interview lasted approximately $90 \mathrm{~min}$. Discussions were recorded on a digital recorder, allowing the facilitator (graduate student and author) to lead the discussion rather than be distracted by taking 
Table 3. Staff survey questions, with quantitative responses $(n=39)$ on $Q 1-12$, concerning the use of volunteers at the Minnesota Landscape Arboretum.

Responses [no. (\%)]

Question

Yes No

1. Do you currently utilize volunteers in your job assignment?

$33(87) \quad 5(13)$

2. Have you previously utilized volunteers in your job assignment?

3. On average how many volunteers do you utilize during your busiest season?

4. How much time do you spend preparing for volunteers on a monthly basis?

$\begin{array}{lllll}33(89) & 4(11) & & \\ 1-5 \text { vols }^{\mathrm{z}} & 5-10 \text { vols } & 10-15 \text { vols } & >15 \text { vols } & \\ 16(48) & 8(24) & 3(9) & 6(18) & \\ \text { None } & 1-3 \mathrm{~h} & 3-5 \mathrm{~h} & 5-7 \mathrm{~h} & >7 \mathrm{~h} \\ 4(12) & 16(48) & 6(18) & 4(12) & 3(9)\end{array}$

5. Do you call volunteers if you no longer need them for their scheduled time?

6. Do you experience a high volunteer turnover within a calendar year?

7. Do you thank your volunteers every time they volunteer with you?

8. Are you willing to take on new volunteers?

9. Do you feel encouraged by your supervisor to utilize volunteers in completing your job assignment?

10. Do you feel that you are expected to utilize volunteers to complete your job assignment?

11. Do you feel sufficiently prepared to work with volunteers?

12. In your opinion, are the volunteers helping to further the mission of the Minnesota Landscape Arboretum?

13. How do you utilize volunteers?

14. In what areas can you expand your current volunteer usage?

15. What has caused you not to use volunteers in completing your job assignment?

16. How could the Volunteer Department help you make better use of the volunteer pool?

${ }^{\mathrm{z}}$ vols $=$ volunteers.

notes. Participants were informed of the recording to compile the data, and it was explained that their identity would be anonymous; the recording would be destroyed as soon as the information had been compiled into a text format. No staff were present, including the MLA volunteer coordinator, as recommended by Krueger (1994). At the conclusion of the focus group, participants were given a horticultural book written by a local author in appreciation of their time.

The staff survey questions were generated by the authors (Table 3 ). The surveys were distributed at the Dec. 2003 staff meeting. Supervisors were asked to deliver copies of the surveys to those employees who were not in attendance. Staff were given 1 month to complete the survey. A week before the surveys were due an e-mail

Table 4. Profile of focus group participants volunteering at the Minnesota Landscape Arboretum.

\begin{tabular}{|c|c|c|c|c|c|c|}
\hline \multirow{2}{*}{$\begin{array}{l}\text { Focus group } \\
\text { session }\end{array}$} & \multicolumn{2}{|c|}{ Gender } & \multicolumn{4}{|c|}{ Volunteer history (years) } \\
\hline & Female (no.) & Male (no.) & $4-5$ & $6-9$ & $10-15$ & $<16$ \\
\hline Evening & 4 & 0 & 1 & 1 & 2 & 0 \\
\hline Morning & 7 & 3 & 4 & 2 & 3 & 1 \\
\hline Afternoon & 2 & 3 & 1 & 1 & 2 & 1 \\
\hline Total & 13 & 6 & 6 & 4 & 7 & 2 \\
\hline
\end{tabular}

reminder was sent to all staff. Surveys were returned to a sealed box in the MLA mailroom.

\section{Results}

The focus groups, each with four to 10 people, represented a cross-section of volunteer duties and length of volunteer service at the MLA (Table $4)$.

Of the 77 staff surveys distributed,
Neither

agree nor Strongly disagree Disagree disagree

$1(3)$

$10(32)$

0
39 were returned, a $51 \%$ response rate (Table 3). Eighty-seven percent of the staff reported using volunteers in their jobs; $74 \%$ of the staff responding agreed or strongly agreed that they feel encouraged to utilize volunteers to complete their job assignment. Of those respondents who utilize volunteers, $79 \%$ reported spending $5 \mathrm{~h}$ or less per month preparing for volunteer shifts. When the respondents were 
asked why they do not utilize volunteers to complete their job assignments, the responses were categorized into three groups: 1) job requires specialized skills or abilities; 2) time constraints; and 3 ) the job is not appropriate for volunteers.

To identify the future direction of the MLA volunteer program, focus group and survey responses were compiled into either communication/general information or furthering the mission and organizational objectives.

COMMUNiCATION/GENERAL INFORMATION RESPONSES (FOCUS GROUP). In focus groups, volunteers discussed the types of communication they have had with the volunteer program and MLA staff. The primary method of communication with established volunteers is the newsletter, detailing volunteer opportunities with a detachable return form. Upon receipt, completed forms are distributed to respective staff members, who are then responsible for contacting potential volunteers. Focus group participants said that they have returned the form from the newsletter and seldom receive a reply. This lack of response makes some volunteers wonder whether the MLA has too many volunteers. Participants furthered this conversation by stating that they are available to volunteer but are rarely contacted directly by MLA staff or the volunteer program. Many new or potential volunteers who are eager to get involved rely on communication from the staff. A breakdown in communication between staff and potential volunteers occurs when MLA staff do not have enough time to make phone calls or communicate directly with volunteers.

Focus group participants suggested several new ways of communicating to volunteers (Table 5), including opportunities that allow volunteers to be more proactive in signing up for volunteer shifts. Additional recommendations included a bulletin board for staff to post volunteer opportunities. Participants also stressed the need for online postings to serve a wider range of volunteers. Such an arrangement would allow volunteers to learn of MLA's current volunteer needs and sign themselves up, rather than waiting for staff to call them. In addition, volunteers asked that an all-inclusive list of volunteer opportunities/job descriptions be created. Participants

Table 5. Volunteer focus group and staff survey recommendations for future volunteer involvement at the Minnesota Landscape Arboretum (MLA).

Immediate actions

- Add "to use volunteers more effectively" to Strategy 7 on the MLA's strategic plan, along with strategies to recruit new volunteers, to read: "Seek and generate resources to accomplish our goals.

A. Objective: Develop annual funding scenarios and approaches to meet various economic and weather conditions.

B. Objective: Develop membership plans.

C. Objective: Use volunteers more effectively and develop strategies to recruit new volunteers."

- Inform volunteers of the rewards and benefits of recording volunteer hours. Include how to record volunteer hours, where volunteer timesheets are kept and what rewards the volunteers receive. Ideally, volunteers should receive this in a handbook.

- Create a volunteer opportunities bulletin board where staff can post job descriptions and volunteers can be proactive by signing up for new jobs.

- Develop and maintain an all inclusive list of volunteer opportunities/job descriptions. Ideally, volunteers should receive this in a handbook.

- Update the volunteer application to capture more specific information, including volunteers' skills and abilities.

\section{Ongoing efforts}

- Communicate the MLA's mission and strategic plan objectives to volunteers on a regular basis. These communications could include:

- Posting mission and strategic plan on a volunteer bulletin board

-Distribute and discuss the mission and strategic plan objectives at volunteer orientation

-Discuss with volunteers one-on-one and in larger groups

- Print the mission on the volunteer timesheets

- Post mission and strategic plan on a MLA volunteer website

-Include mission with annual thank-you to volunteers

-Describe specific examples of how the volunteers are helping to further the mission and strategic plan objectives

- Establish volunteer captain/staff liaison model for each volunteer area at the MLA, to streamline and create efficient placement and management of volunteers.

- Establish guidelines to measure volunteer productivity utilizing the MLA's mission and organizational objectives.

- Establish a central area where volunteers can interact with one another, sign-up for volunteer duties and leave their personal belongings while volunteering.

- Measure effectiveness of volunteer trainings and orientations by having the participants complete an evaluation at each event.

- Continue conversation, in focus groups, with the staff and volunteers on how to strengthen the volunteer program.

- Provide all new volunteers with a ride on the tram at orientation to expand their understanding of the MLA firsthand.

- Offer regular, ongoing in-service trainings concerning topics relevant to volunteer jobs and the MLA.

- Integrate active learning opportunities, such as decision cases into volunteer trainings and orientations.

- Publicize the volunteer program, promoting opportunities while highlighting the accomplishments of the MLA volunteers.

- Establish electronic communications-a listserve to communicate with volunteers and links on the MLA website for updates and information.

stressed, however, that in order for volunteers to be proactive, a contact person should be listed with every job posting.

COMMUNiCATION/GENERAL INFORMATION RESPONSES (STAFF SURVEY). Working toward improved communi- cation between staff and the volunteer program, the survey probed how MLA staff could utilize volunteers more fully (Table 3 ). Survey respondents reported needing more information about the skills volunteers have and their readiness to start volunteering in 
order to improve volunteer scheduling. Staff suggested updating the volunteer application to collect additional information, and other programmatic changes (Table 5).

When asked how the volunteer department could help staff make better use of volunteers, staff suggested more publicity for volunteers and promoting the value of the volunteers to the MLA. Showing public appreciation for volunteers while marketing to prospective volunteers ties in with the continual need to recruit new volunteers.

Mission AND ORGANIZATIONAL OBJECTIVE RESPONSES (FOCUS GROUP). When presented with the mission, focus group participants expressed their individual level of comfort with the mission as an average of 4.72 on a five-point Likert scale, with one being very uncomfortable and five being very comfortable (Likert, 1967). The level of agreement with the mission amongst the participants was an average of 4.31 .

Focus group participants agreed that the mission makes sense and that they knew the basic concept of the mission. The volunteers identified the areas where their work impacts the mission, including educating the public as well as inspiring and delighting the visitors. Participants suggested that they could further the mission through programs that make the MLA and its resources more visible to a wider audience. One such program suggested by the focus groups includes sending volunteers as ambassadors into the local community to senior centers and other organizations to inform them about the MLA and arrange tours.

Focus group participants reported that the organizational objectives in the strategic plan made sense to them and expressed their individual level of comfort with the objectives as an average of 4.31 on a five-point Likert scale (Likert, 1967). The level of agreement with the organizational objectives amongst the participants was an average of 4.67. Volunteers raised the concern that there was no mention of them in the strategic plan; they recommended adding the statement: "MLA will work to use volunteers more effectively and to develop strategies surrounding ways to recruit new volunteers."

The focus group participants agreed that volunteers are essential to the MLA's work. With volunteer opportunities across the organiza- tion, participants felt that their work is significantly contributing to the mission and organizational objectives of the MLA.

The focus groups identified the specific item in the current strategic plan "Create a department of visitor services" as one new way that volunteers could help to further the MLA's organizational objectives by fulfilling specific needs for visitors. Second, the focus groups suggested volunteers could further the organizational objectives if more volunteer opportunities could be completed from home or in the local community. Most importantly, volunteers asked to be regularly informed about the organizational objectives, and what work needs to be accomplished in order to help further these objectives (Table 5).

MISSION AND ORGANIZATIONAL OBJECTIVE RESPONSES (STAFF SURVEY). The responses to the staff survey show MLA staff strongly agreeing that the volunteers are essential to further the mission (Table 3). Many staff commented that the work would not get done without the volunteers.

\section{Discussion}

Focus groups are a valid research tool if they are used carefully and correctly to solve a problem such as program development and improvement (Krueger, 1994). Specifically, our focus groups were valuable in providing input into the future direction of the MLA volunteer program by identifying the needs, wants, and preferences of the volunteers, all of which are critical factors in strengthening the volunteer program. These recommendations have been used to enhance the volunteer program.

Our research supports the conclusion of others (Haynes and Trexler, 2003 ) that when training and communication are inadequate, volunteers are likely to feel their time is not valued by the institution, and they volunteer elsewhere. All focus group participants supported the need for more communication, the opportunity to be proactive and sign up for volunteer duties, and communication on what volunteers can do to further the mission and organizational objectives of the MLA. When volunteers' needs are met, they are more likely to be committed to the work and goals of the institution (Nelson et al., 1995).

The staff survey allowed for insti- tution-wide input in a timely fashion, while utilizing minimal resources. Allen (1995) concluded that staff members need to be encouraged to use volunteers, and our research supports this finding. For botanic gardens or arboreta seeking to strengthen and improve their volunteer programs, focus groups and staff surveys can be valuable tools to discuss volunteer involvement, identify areas where change is needed, and align these changes with the mission of the organization.

\section{Literature cited}

Allen, K. 1995. Creating more effective volunteer involvement. Points of Light Foundation, Washington, D.C.

Andreasen, A.R. 1983. Cost-conscious marketing research. Harvard Business Rev. 83(4):74-79.

Barton, S.S, J. Mercer and C.J. Molnar. 1996. Using focus groups to determine market potential for wildflower sod. HortTechnology 6(3):271-276.

Clary, E.G. and J. Miller. 1986. Socialization and situational influences on sustained altruism. Child Dev. 57:1358-1369.

Clary, E.G., M. Snyder, and R.Ridge. 1992. Volunteers' motivations: A functional strategy for the recruitment, placement and retention of volunteers. Nonprofit Mgt. Leadership 2(4):333-350.

Connelly, T., Jr. 1989. Establishing an organizational philosophy: A cornerstone for productivity in the volunteer organization. J. Volunteer Administration 7(3):1-6.

Cummins, R. 1998. Leadership for volunteers: The way it is and the way it could be. J. Ext. 36(5).24 Apr. 2004. < http://www. joe.org/joe/1998october/tt2.html>.

Czaja, R. and J. Blair. 1996. Designing survey: A guide to decisions and procedures. Pine Forge Press, Thousand Oaks, Calif.

Faber, B.J. and J. Wycoff. 1991. Bringing the customer into focus. Training 28(5):4l-44.

Francies, G.R. 1983. The volunteer-needs profile: A tool for reducing turnover. J. Volunteer Administration 1:17-33.

Haynes, C. and C.J. Trexler. 2003. The perceptions and needs of volunteers at a university affiliated public garden. HortTechnology 13(3):552-556.

Kipperman, S.P. 1995. Motivating volunteers: Make the most of commitment to the cause. Leadership 3(Oct.-Dec.):21-22.

Krueger, R.A. 1994. Focus groups: A practical guide for applied research. 2 nd ed. Sage Publ., Thousand Oaks, Calif. 
Likert, R. 1967. The method of constructing an attitude scale, p. 90-95. In: M. Fishbein (ed.) Readings in attitude theory and measurement. Wiley, New York.

Maxim, P.S. 1999. Quantitative research methods in the social sciences. Oxford University Press, New York.

Meyer, M.H. and A.F.G. Barker. 1997. Teaching horticulture and Native American agricultural traditions: An annotated bibliography. HortTechnology 7(2):110118.

Nelson, H.W., C.C. Pratt, C.E. Carpenter, and K.L. Walter. 1995. Factors affecting volunteer long-term care ombudsman organizational commitment and burnout. Nonprofit Voluntary Sector Quarterly 24(3):213-233.

Omoto, A.M. and M. Snyder. 1990. Basic research in action: Volunteerism and society's response to AIDS. Personality Social Psychology Bul. 16:152-166.

Rea, L.M. and R.A. Parker. 1992. Designing and conducting survey research: A comprehensive guide. Jossey-Bass, San Francisco.

Schrock, D.S. 1998. A functional approach to understanding and assessing the motivation and retention of university extension Master Gardener volunteers. PhD Diss., Dept. of Horticulture, Univ. of Minnesota, St. Paul.

Sirken, A.F. and M.P. McDermott. 1996. The volunteer leader's role in keeping members. Leadership 46(1):67-68, 74.

Socolofsky, K. 1991. A team approach to volunteer management. Public Garden 6(2):12-15.

Vineyard, S. 1993. Megatrends \& volunteerism. Heritage Arts, Downers Grove, Ill. 